\title{
QUESTÕES SOBRE TRADUÇÃO \\ a DiDier Lamaison
}

Didier Lamaison é Professor de Letras Clássicas, ensaísta e dramaturgo. Seu primeiro contato com a língua portuguesa se deu através do "Soneto da Fidelidade", de Vinícius de Moraes, e do poema "José", de Carlos Drummond de Andrade, quando trabalhava como Professor Leitor de francês na Universidade Federal de Pernambuco, em 1980. É tradutor de Carlos Drummond de Andrade, Ferreira Gullar, Augusto dos Anjos, Mário Pontes, Machado de Assis, Fernando Pessoa assim como de letras de músicas de Caetano Veloso e Chico Buarque. Pelo trabalho de tradução da obra poética de Carlos Drummond de Andrade - na França, editada pela Gallimard -, recebeu em 1991 o prêmio Nelly Sachs. Didier Lamaison é também autor do romance noir Édipo Rei-traduzido do mito, de 1994. Foi eleito, no dia 4 de junho de 2009, para Cadeira no 1 do Quadro dos Sócios Correspondentes da Academia Brasileira de Letras, sucedendo o escritor português Antônio Alçada Baptista.

Edmar Guirra (Mestrando do Programa de Pós-Graduação em Letras Neolatinas da UFRJ)

\section{Quais os maiores desafios que o senhor enfrentou ao traduzir a obra do poeta brasileiro Carlos Drummond de Andrade?}

Do ponto de vista formal, primeiramente, foi conseguir compreender, sentir a multiplicidade de tons e de registros de Drummond. O poeta passa o tempo todo de uma língua coloquial a uma metáfora muito rebuscada. É muito difícil, para estrangeiros, perceber e entender essas mudanças de tom. Contudo, o mais difícil do ponto de vista da forma foi a tradução dos textos de inspiração mais simples e popular, por exemplo, o poema "José", em que, mudando uma só palavra na tradução, obtinha-se outro sentido. Cito também "O caso do vestido" que é um exercício de poesia popular de Drummond, em heptassílabos. Nesses casos, o ritmo é, igualmente, uma questão difícil na tradução.

Do ponto de vista cultural, foi menos difícil porque eu sempre tinha um amigo brasileiro, não muito distante, para me explicar o contexto de tal poema, a alusão a um fato ou a um detalhe geográfico de Itabira, por exemplo. 
2. Jean-Michel Massa já havia traduzido uma seleção de poemas de Drummond. Qual a relação de sua tradução com esta tradução? O senhor a evitou ou a considerou?

Eu conhecia a tradução de Massa, embora não o tenha conhecido pessoalmente. Posso dizer que, quando via que Jean-Michel Massa havia traduzido um poema para sua antologia, eu aproveitava para não retomá-lo na minha tradução. Eu pensava que se tal poema já havia sido traduzido para a língua francesa, poderia aproveitar para traduzir outros. Porém, alguns poemas foram retomados. Os mais célebres, por exemplo, como "No meio do caminho", eu não poderia deixar de retraduzir. Não concordava com as traduções de Jean-Michel Massa. Achava que o público francês poderia ter uma segunda tradução. Não que a minha tradução fosse melhor ou definitiva, mas era outra.

3. Que especificidades o senhor vê na tradução de poesia? Que perdas lhe parecem mais graves? A edição bilingue, de alguma maneira, interfere na atitude do tradutor?

No caso da poesia, o tradutor goza de maior liberdade. Não que ele fique mais à vontade, mas há um jogo na tradução da poesia que é prazeroso. Sabendo que é impossível traduzir poeticamente uma língua na outra, por diversas razôes que muitos já analisaram, o desespero que o tradutor encontra em relação à impossibilidade de traduzir tal verso é compensado pela tradução do verso seguinte. A língua francesa permite fazer uma tradução dando uma expressão colorida que não existiria no original. Quero dizer que se, em um primeiro verso, o francês fica muito distante do português, no verso seguinte o francês oferece mais possibilidades do que o português para dizer a mesma coisa. Esse jogo de compensação é muito interessante. Isso não ocorre, ou pouco ocorre, na tradução da prosa.

A respeito da edição bilíngue, posso dizer que seu efeito é o da liberação do tradutor que, quando não consegue traduzir uma imagem ou um verso, tem na versão original uma forma de compensação da insuficiência do seu trabalho.

4. O senhor tem eventualmente a sensação, como tradutor, de desenvolver ou mesmo de superar o original?

Superar, melhorar, não. Isso entra no tal jogo de compensações. Mas confesso que, às vezes, temos algumas alegrias. Penso: "Se Drummond tivesse cogitado essa tal possibilidade que a língua francesa 
oferece, ele teria gostado e escolhido a versão francesa." Mas não devemos exagerar. O resultado é sempre uma frustração para o tradutor. O texto original sempre é o ideal a atingir. Às vezes acontecem essas compensaçôes que são, geralmente, uma sorte no trabalho da tradução da poesia.

5. Como tradutor literário, o senhor se depara frequentemente com o intraduzivel? O que seria o intraduzivel?

A intraduzibilidade é uma situação que se encontra a cada passo no trabalho de tradução. Como disse, a questão do ritmo é um exemplo. O problema das denotações também. Quando Drummond nomeia realidades brasileiras que não existem em francês, deparamo-nos com o intraduzível. A palavra cachaça é, a esse respeito, exemplar. Temos em francês o equivalente eau de vie, mas que não tem nada a ver com cachaça. Então, o tradutor se pergunta: o que fazer nesses casos? Particularmente, opto por manter a palavra "cachaça” e acrescentar uma nota. Às vezes, esse problema da denotação pode ser resolvido quando se encontra uma realidade francesa exatamente equivalente, mesmo não sendo idêntica. Percebo que muitos tradutores têm pavor dessas palavras, dessas realidades do país estrangeiro que não podem encontrar equivalente na língua de chegada. Para mim não há problema, procuro sempre outros recursos. Acrescento que o intraduzível é tudo aquilo que faz parte do patrimônio imaginário de cada cultura, e isso não se pode traduzir. Por exemplo, a palavra borboleta tem mais ou menos as mesmas conotações em português e em francês. Já a palavra mar e tudo ao seu redor não têm as mesmas conotaçōes nas duas línguas. Na França, o mar foi o espaço de combate, de guerras, sempre visto como um inimigo do país. E esse sentido quase não existe no português do Brasil, onde o mar é o aliado, o natural. Há, então, um mundo de conotaçóes ao redor da palavra mar que não é o mesmo nas culturas francesa e brasileira. Esse mundo imaginário não pode ser recriado numa tradução, e constitui, portanto, um exemplo de "intraduzível”.

6. Qual o lugar da tradução, e mais especificamente da tradução literária, no âmbito da cultura globalizada?

Essa é uma questão interessante e difícil que se pode responder de diversas maneiras. Primeiramente, poderia dizer que o império da língua inglesa acaba com toda tradução. Quero dizer que tudo o que 
dá valor ao exercício da tradução é o confronto entre duas culturas; como duas culturas podem, digamos, se amar, do ponto de vista da tradução. $\mathrm{O}$ inglês, nesse aspecto, acaba com a globalização de uma língua. Podemos dizer que um tailandês falando inglês, enquanto uma língua global, é como se fosse, metaforicamente, um "desesperanto". Quando o estrangeiro de qualquer lugar do mundo fala esse "desesperanto", não há tradução. O estrangeiro "passa as coisas" de um "lugar", de sua cabeça e cultura, para outro, sem haver uma comunicação nesse caminho. O "desesperanto" é tão pobre e rudimentar que pesquisas asseguram que, com menos de mil palavras dessa língua, podemos nos comunicar em qualquer lugar no mundo. É uma língua que responde a necessidades muito simples. Portanto, falar o "desesperanto", a língua inglesa franca, hoje, acaba com possibilidades de tradução. Tendo falado sobre o império linguístico que essa língua exerce hoje no mundo, defendo a importância da tarefa de tradução no mundo globalizado: a tradução é uma ferramenta para preservar a diversidade cultural do mundo, encenando um papel de urgência para salvar o que ainda se pode salvar das culturas, da multiculturalidade.

7. Qual o lugar da literatura brasileira - e, mais genericamente, $d a$ lingua portuguesa - em sua formação como escritor?

Nos meus trabalhos, a língua portuguesa tem o mesmo papel que a língua latina ou a língua grega, das quais sou tradutor também. Penso que, fundamentalmente, escrever é traduzir. Não há nenhum escritor que não seja um tradutor. Não tomo, aqui, a palavra traduzir como sinônimo de exprimir.

Por exemplo, o título do meu romance Oedipe roié seguido da inscrição "traduit du mythe", que não foi compreendida por muitos. Quis dizer que existe a língua do mito e, a partir dessa língua original, faço a tradução francesa da língua do mito grego de Édipo Rei. Sófocles também foi tradutor dessa língua do mito. O mito existia antes de Sófocles; veja a multiplicidade de vozes que ele admite. O que fiz foi uma tradução dessa língua global do mito.

Quero dizer, com esse exemplo, que toda literatura que existe antes de se começar a escrever vive no escritor que está escrevendo. Se ele escreve sobre o amor, já existem na sua memória muitas histórias parecidas com a que escreve. $\mathrm{O}$ que o escritor faz é uma escolha de elementos na sua memória para criar uma obra nova cujo resultado é uma tradução dessa língua original falada e transmitida 
pela nossa cultura, pelo conhecimento da condição humana que resultou dessa cultura, desse passado e da leitura de obras. Concluo dizendo que meu trabalho de tradutor é sempre ligado ao meu trabalho de escritor. Traduzir um verso de Drummond é como traduzir uma ideia que tenho que exprimir e dar uma versão dessa ideia, como dou uma versão a um verso de Drummond.

\section{Resumo}

O tradutor e romancista Didier Lamaison responde a questôes sobre sua experiência como tradutor do poeta Carlos Drummond de Andrade, o intraduzível, a tradução como forma de mutação e renovação do texto original e as especificidades da tradução de poesia.

\begin{abstract}
The translator and novelist $\mathrm{Di}$ dier Lamaison answers to questions about his experience as a translator of the poet Carlos Drummond de Andrade, the untranslatable, the translation as a form of change and original's renewal and features in the translation of poetry.
\end{abstract}

\section{Résumé}

Le traducteur et romancier Didier Lamaison répond à des questions sur son expérience en tant que traducteur du poète Carlos Drummond de Andrade, sur l'intradusibilité, sur la traduction comme forme de changement et de renouvellement du texte originel et sur les spécificités de la traduction de poésie.
Palavras-chave: Lamaison; tradução; tradução de poesia.

Key words: Lamaison; translation; translation of poetry.

Mots-clés: Lamaison; traduction; traduction de poésie. 